\title{
Role of potassium and calcium channels in sevoflurane-mediated vasodilation in the foeto-placental circulation James Jarman ${ }^{\dagger 1,2}$, Chrisen H Maharaj ${ }^{\dagger 1,2}$, Brendan D Higgins ${ }^{1,2}$, Rachel F Farragher ${ }^{1}$, Christopher D Laffey ${ }^{3}$, Noel M Flynn ${ }^{1}$ and John G Laffey*1,2
}

Address: ${ }^{1}$ Department of Anaesthesia, Clinical Sciences Institute, National University of Ireland, Galway Ireland, ${ }^{2}$ National Centre for Biomedical Engineering Sciences, National University of Ireland, Galway, Ireland and ${ }^{3}$ Public Analysts Laboratory, Newcastle, Galway, Ireland

Email: James Jarman - jamesjarman@hotmail.com; Chrisen H Maharaj - chrisenm@gmail.com; Brendan D Higgins - brendan.higgins@nuigalway.ie; Rachel F Farragher - rachel.farragher@hse.ie; Christopher D Laffey - christopher.laffey@hse.ie; Noel M Flynn - noel.flynn@hse.ie; John G Laffey* - john.laffey@nuigalway.ie

* Corresponding author †Equal contributors

Published: 10 June 2009

BMC Anesthesiology 2009, 9:4 doi:10.1/86/147|-2253-9-4
Received: 8 December 2008

Accepted: 10 June 2009

This article is available from: http://www.biomedcentral.com/I47I-2253/9/4

(c) 2009 Jarman et al; licensee BioMed Central Ltd.

This is an Open Access article distributed under the terms of the Creative Commons Attribution License (http://creativecommons.org/licenses/by/2.0), which permits unrestricted use, distribution, and reproduction in any medium, provided the original work is properly cited.

\begin{abstract}
Background: Sevoflurane has been demonstrated to vasodilate the foeto-placental vasculature. We aimed to determine the contribution of modulation of potassium and calcium channel function to the vasodilatory effect of sevoflurane in isolated human chorionic plate arterial rings.
\end{abstract}

Methods: Quadruplicate ex vivo human chorionic plate arterial rings were used in all studies. Series I and 2 examined the role of the $\mathrm{K}^{+}$channel in sevoflurane-mediated vasodilation. Separate experiments examined whether tetraethylammonium, which blocks large conductance calcium activated $\mathrm{K}^{+}\left(\mathrm{K}_{\mathrm{C}^{++}}\right)$channels (Series IA+B) or glibenclamide, which blocks the ATP sensitive $\mathrm{K}^{+}$ $\left(K_{\text {ATP }}\right)$ channel (Series 2), modulated sevoflurane-mediated vasodilation. Series $3-5$ examined the role of the $\mathrm{Ca}^{++}$channel in sevoflurane induced vasodilation. Separate experiments examined whether verapamil, which blocks the sarcolemmal voltage-operated $\mathrm{Ca}^{++}$channel (Series 3), SK\&F 96365 an inhibitor of sarcolemmal voltage-independent $\mathrm{Ca}^{++}$channels (Series $4 A+B$ ), or ryanodine an inhibitor of the sarcoplasmic reticulum $\mathrm{Ca}^{++}$channel (Series $5 A+B$ ), modulated sevofluranemediated vasodilation.

Results: Sevoflurane produced dose dependent vasodilatation of chorionic plate arterial rings in all studies. Prior blockade of the $\mathrm{K}_{\mathrm{Ca}^{++}}$and $\mathrm{K}_{\mathrm{ATP}}$ channels augmented the vasodilator effects of sevoflurane. Furthermore, exposure of rings to sevoflurane in advance of TEA occluded the effects of TEA. Taken together, these findings suggest that sevoflurane blocks $\mathrm{K}^{+}$channels. Blockade of the voltage-operated $\mathrm{Ca}^{++}$channels inhibited the vasodilator effects of sevoflurane. In contrast, blockade of the voltage-independent and sarcoplasmic reticulum $\mathrm{Ca}^{++}$channels did not alter sevoflurane vasodilation.

Conclusion: Sevoflurane appears to block chorionic arterial $\mathrm{K}_{\mathrm{Ca}^{++}}$and $\mathrm{K}_{\mathrm{ATP}}$ channels. Sevoflurane also blocks voltage-operated calcium channels, and exerts a net vasodilatory effect in the in vitro foeto-placental circulation. 


\section{Background}

Sevoflurane has gained widespread acceptance in obstetric anaesthesia [1-3], and has an excellent clinical profile in this population $[2,3]$. We have recently demonstrated that sevoflurane vasodilates the foeto-placental vasculature in vitro, in part by a mechanism that is mediated via inhibition of lipoxygenase [4]. However, the potential for sevoflurane to cause vasodilation via modulation of calcium and potassium ion channel function in this circulation remains to be determined.

The potential for volatile anaesthetic agents to modulate vascular tone via alterations in calcium and potassium ion channel function in other circulations is clear. Halothane has been demonstrated to vasodilate conducting and resistance coronary arteries via activation of the $\mathrm{K}_{\text {ATP }}$ channel [5]. Sevoflurane-mediated activation of potassium ion $\left(\mathrm{K}^{+}\right)$channels would increase potassium conductance, causing myocyte hyperpolarisation and vasodilation [6]. Two types of $\mathrm{K}^{+}$channels of functional importance in the vasculature are the $\mathrm{Ca}^{++}$-activated $\mathrm{K}^{+}\left(\mathrm{K}_{\mathrm{Ca++}}\right)$ channels and the ATP-sensitive $\mathrm{K}^{+}\left(\mathrm{K}_{\mathrm{ATP}}\right)$ channels [6]. The effects of sevoflurane on to $\mathrm{K}^{+}$channels appear to be depend on channel subtype. Sevoflurane has been demonstrated to selectively increase coronary collateral blood flow via mechanisms that appear to be independent of $\mathrm{K}_{\text {ATP }}$ channel activation [7], but which involve activation of $\mathrm{K}_{\mathrm{Ca}++}$ channels [8].

Sevoflurane could also cause vasodilation via inhibition of one or more calcium $\left(\mathrm{Ca}^{++}\right)$channels. At least three distinct types of $\mathrm{Ca}^{++}$channels are of importance in the vasculature: the sarcolemmal voltage-operated $\mathrm{Ca}^{++}$channel (VOCC) [9]; sarcolemmal voltage-independent $\mathrm{Ca}^{++}$ channels (VICC) $[9,10]$; and sarcoplasmic reticulum calcium channel. Of interest, halothane has been demonstrated to activate VICC channel activity, while sevoflurane did not have any effect on these channels, in the rat aorta [9].

We therefore hypothesized that sevoflurane would vasodilate the foeto-placental circulation by a mechanism involving alterations in the activity of potassium and/or calcium channels. Specifically, we hypothesized that sevoflurane activates $\mathrm{K}^{+}$channels, causing myocyte hyperpolarisation and vasodilation. Our second hypothesis was that sevoflurane inhibits $\mathrm{Ca}^{++}$channels, thereby reducing intracellular $\mathrm{Ca}^{++}$concentrations, and thus directly reduces vessel tension.

\section{Methods}

Following ethical committee approval, and written informed patient consent, term placentae were obtained after both vaginal and caesarean delivery under neuraxial anaesthesia from healthy parturients. Exclusion criteria included pre-existing hypertension, intra-uterine growth retardation, pre-eclampsia, multiple pregnancies, and patients with pregnancy induced hypertension, hepatitis and HIV infection.

All studies followed a randomised, controlled, paired design. Samples of the second-order chorionic plate arteries were taken within 120 minutes of delivery and placed directly into ice-cold pyrogen-free physiologic saline solution. Four chorionic rings, each $3 \mathrm{~mm}$ in length, from a single artery from each placenta, were isolated, mounted in PSS at $37^{\circ} \mathrm{C}$, and equilibrated with $95 \% \mathrm{O}_{2}-5 \% \mathrm{CO}_{2}$ in tissue baths (10 ml capacity) as previously described $[4,11]$ (Figure 1). Samples of the solution were intermittently analyzed for $\mathrm{P}_{\mathrm{O} 2}, \mathrm{P}_{\mathrm{CO} 2}$ and $\mathrm{pH} . \mathrm{P}_{\mathrm{CO} 2}$ was maintained in the range $3.5-4.5 \mathrm{kPa}$, and $\mathrm{pH}$ was maintained in the range $7.35-7.45$ in all experiments. Rings were threaded onto a horizontally fixed platinum surgical wire (300 $\mu \mathrm{m}$ diameter). A second hook, connected to an isometric force transducer, was then passed through the lumen of the ring. Isometric tension was recorded as a function of time using a transducer system (Grass FT03, Quincy, MA) (Figure 2).

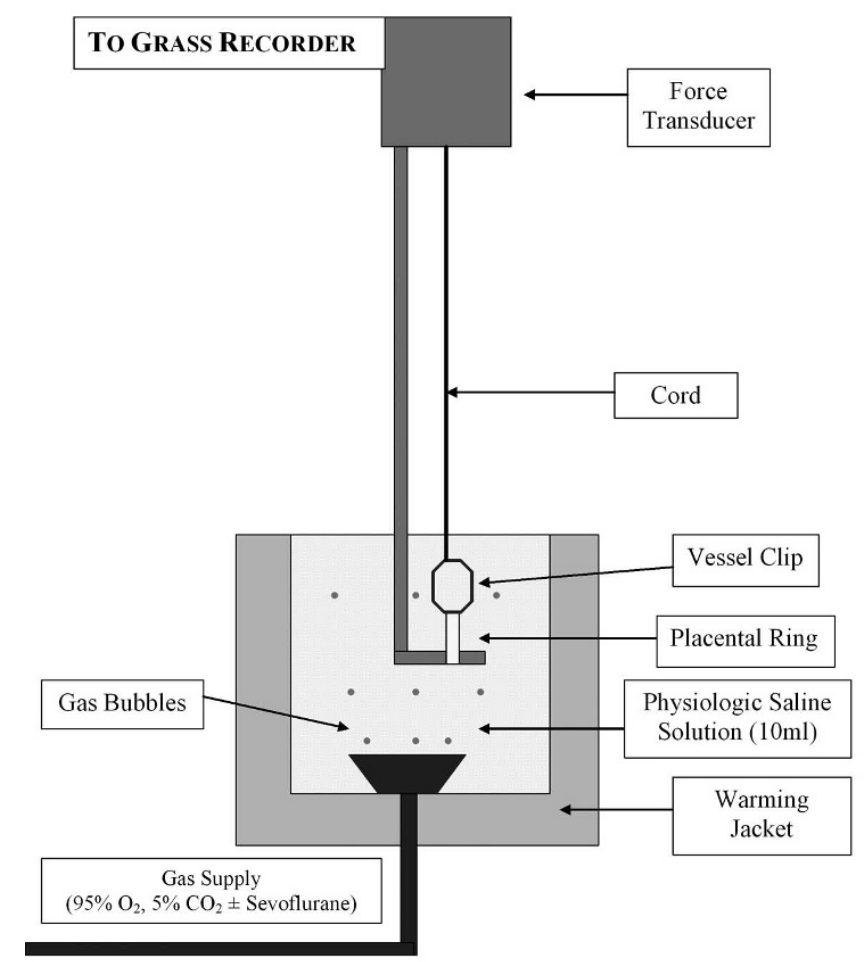

Figure I

Schematic representation of the ex vivo incubation model system used in the isolated vessel experiments. 


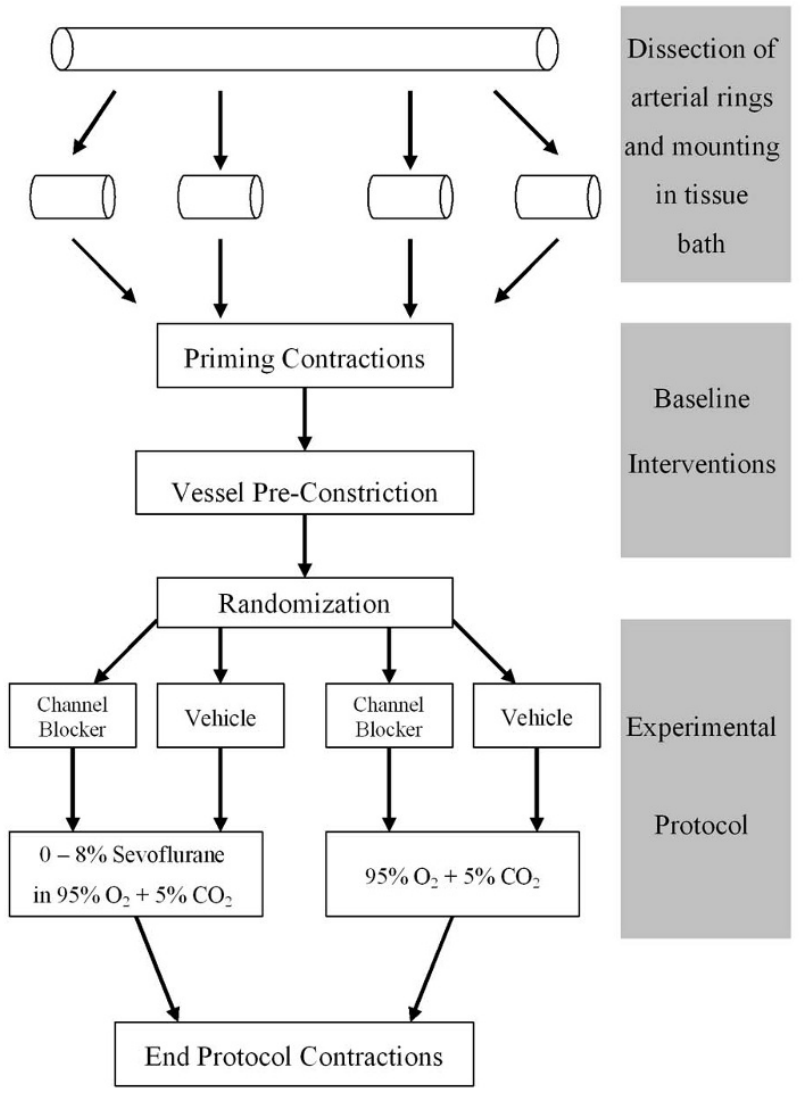

\section{Figure 2}

Schematic representation of the experimental design used in each experimental series, with the exception of series IB.

\section{Baseline Interventions}

Following a 60 minute equilibration period, an optimal pre-tension of $2.00 \mathrm{~g}$ for each chorionic plate arterial ring was utilised [4]. Priming contractions were induced by exposing the rings three times to $80 \mathrm{mM} \mathrm{KCl}$ solution (iso-osmotically substituted for $\mathrm{NaCl}$ ), and pre-tension re-established at the end of each 5 minute exposure by rinsing with physiologic saline solution (Figure 2). The rings were then submaximally pre-constricted with the thromboxane analog U46619 (9,11-dideoxy-11 $\alpha, 9 \alpha$ epoxymethanoprostagladin F2 $\alpha, 5 \times 10-6 \mathrm{M})$. Once a stable plateau contractile response was obtained, the rings were allowed to remain at the plateau tension for $30 \mathrm{~min}$ utes.

\section{$\boldsymbol{K}^{+}$Channel Experimental Series}

Each experimental series followed a similar overall design (Figure 2). Series 1 examined the role of the calcium activated $\mathrm{K}^{+}\left(\mathrm{K}_{\mathrm{Ca}++}\right)$ channel in mediating the vasodilatory effect of sevoflurane. Tetraethylammonium (TEA), which at lower doses $\left(1-3 \times 10^{-2} \mathrm{M}\right)$, blocks large conductance calcium activated $\mathrm{K}^{+}\left(\mathrm{K}_{\mathrm{Ca++}}\right)$ channels [12-14] was utilised in these experiments. Series $1 \mathrm{~A}$ determined whether prior incubation with TEA modulated the vasodilation produced by sevoflurane. Following U46619 pre-constriction, two rings from each placenta were randomly assigned to receive sevoflurane in the perfusing gas, in $2 \%$ increments sequentially attained at 30 minute intervals, with the remaining two rings serving as controls (Figure $2)$. TEA $\left(1 \times 10^{-2} \mathrm{M}\right)$ was first added to one sevoflurane exposed bath and one control bath, and allowed to equilibrate for 20 minutes, and vehicle added to the remaining baths. This resulted in four groups: (1) control with vehicle (Control); (2) control with TEA (TEA); (3) sevoflurane with vehicle (SEVO); (4) sevoflurane with TEA (SEVO+TEA). Increasing sevoflurane perfusate concentrations from $2 \%-8 \%$ were then sequentially attained at 30 minute

intervals.

Series $1 B$ determined the effect of prior incubation of the rings with sevoflurane on the vasoactive effect of TEA. Following U46619 pre-constriction and the attainment of a plateau contraction, two rings were randomly assigned to receive $8 \%$ sevoflurane in the perfusing gas $\left(95 \% \mathrm{O}_{2}-5 \%\right.$ $\left.\mathrm{CO}_{2}\right)$ or perfusing gas alone. After 60 minutes, TEA $(1 \times$ $10^{-2} \mathrm{M}$ ) was added to one sevoflurane exposed bath and one control bath, and vehicle added to the remaining baths, and the effects measured. Series 2 examined the role of the ATP sensitive $\mathrm{K}^{+}$channel $\left(\mathrm{K}_{\mathrm{ATP}}\right)$ channel in mediating the vasodilatory effect of sevoflurane. Glibenclamide, which at lower doses $\left(1 \times 10^{-5} \mathrm{M}\right)$ specifically blocks the $\mathrm{K}_{\mathrm{ATP}}$ channel $[15,16]$, was utilised in these experiments. Following U46619 pre-constriction, and the addition of $1 \times 10^{-5} \mathrm{M}$ glibenclamide or vehicle, rings were exposed to sevoflurane or vehicle gas alone as described for series $1 \mathrm{~A}$.

\section{$\mathrm{Ca}^{++}$Channel Experimental Series}

Series 3 examined the role of the sarcolemmal voltageoperated $\mathrm{Ca}^{++}$channel (VOCC). Following U46619 preconstriction, verapamil $1 \times 10^{-6} \mathrm{M}$, which specifically blocks the VOCC channel $[9,17,18]$ or vehicle was added, and the rings exposed to sevoflurane or perfusing gas alone as described for series 1A. Series 4 examined the role of the sarcolemmal voltage-independent $\mathrm{Ca}^{++}$channels (VICC) $[9,10]$. SK\&F 96365, which at concentrations in the $10^{-4}-10^{-6} \mathrm{M}$ range specifically blocks the VICC channel $[9,10,19]$, was utilised in these experiments. Series $4 A$ examined whether $3 \times 10^{-5} \mathrm{M}$ SK\&F 96365 blocked sevoflurane-mediated vasodilation. Series $4 B$ examined the effect of higher concentrations of SK\&F $96365\left(1 \times 10^{\text {- }}\right.$ $\left.{ }^{4} \mathrm{M}\right)$. Series 5 examined the role of the sarcoplasmic reticulum $\mathrm{Ca}^{++}$channel $[9,10]$. Ryanodine, which at concentrations of up to $10^{-4} \mathrm{M}$ specifically inhibits sarcoplasmic 
reticulum calcium release $[20,21]$ was utilised in these experiments. Series $5 A$ examined the effect of $5 \times 10^{-6} \mathrm{M}$ ryanodine, while Series $5 B$ determined whether $5 \times 10^{-5} \mathrm{M}$ ryanodine attenuated the vasodilation produced by sevoflurane.

\section{End protocol contractility assessment}

At the end of each experiment, sevoflurane was discontinued, and baseline pre-tension re-established. The contractile response to $80 \mathrm{mM} \mathrm{KCl}$ was then reassessed and data was excluded from the analysis if the maximum final $\mathrm{KCl}-$ induced contraction in control rings was less than $90 \%$ of the initial $\mathrm{KCl}$ response.

\section{Determination of bath sevoflurane concentrations}

The sevoflurane was introduced into the tissue baths in the perfusing gas via a sevoflurane vapouriser (Abbott Inc., Dublin, Ireland). The vapour content of anaesthetic agent in the carrier gas was continuously measured by means of an in-line agent monitor (Datex Capnomac Ultima ${ }^{\circledast}$, Helsinki, Finland). The perfusing gas was continuously sampled downstream from the vapouriser, at a point just proximal to the entry of the gas into the tissue baths. Volatile anaesthetic concentrations increased within 10 minutes to within $10 \%$ of the value dialled on the vapouriser in all experiments. In addition, in a separate series of experiments, the bath concentrations of sevoflurane were verified using gas chromatography-mass spectrometry, for sevoflurane concentrations in the perfused gas of $0-8 \%$, as previously described [4].

\section{Chemicals}

U46619, tetraethylammonium (TEA) $\alpha$, glibenclamide, verapamil, SK \& F 96365, sodium nitroprusside, and all salts were all purchased from Sigma Aldrich (Poole, Dorset, U.K.). Ryanodine was purchased from BIOMOL International L.P. (Exeter, Devon, U.K.). Sevoflurane was purchased from Abbott Inc. (Dublin, Ireland).

\section{Statistical Analysis}

Data are presented as means \pm SD with vasodilation by sevoflurane expressed as a percentage of the submaximal contraction elicited with U46619. The $\mathrm{EC}_{50 \mathrm{r}}$ value, which represents the concentration of sevoflurane required dilate the pre-constricted rings by $50 \%$, was calculated for each ring, in each experimental series. Firstly, the slope and intercept of the line connecting the sevoflurane values immediately below and above $50 \%$ was determined. The $\mathrm{EC}_{50 \mathrm{r}}$ value is calculated by the following formula: $\mathrm{EC}_{50 \mathrm{r}}=$ $10^{\mathrm{X}}$ where $\mathrm{X}=(50$ - Intercept $) /$ Slope. Comparison between control and test rings was made using two way repeated measures analysis of variance, with group as a between subjects factor and percentage sevoflurane as a repeated measures factor. Between group analyses were restricted to comparisons relevant to our a priori hypotheses, and were made using Student's t testing with corrections for multiple comparisons. The null hypothesis was rejected for $\mathrm{p}<0.05$.

\section{Results}

Chorionic plate arterial rings were obtained from 80 placentae from women ((median age, 26 years [range, 18-43 years]; median parity, 1 [range, 0-4]) following uncomplicated full term (median gestation 40 wks [range 3841]) gestation, for these studies. Stable and comparable gas tensions were maintained throughout all experiments, and comparable baseline levels of contractile responses were observed in all series. Post-intervention responses to potassium chloride were not different compared to baseline for any rings studied, and therefore no rings were excluded.

\section{Sevoflurane and the $K+$ Channel}

In Series 1A, blockade of the calcium activated $\mathrm{K}^{+}\left(\mathrm{K}_{\mathrm{Ca}++}\right)$ channel ( $\mathrm{n}=10$ rings per group) with $1 \times 10^{-2} \mathrm{M}$ TEA significantly increased sevoflurane-mediated vasodilation compared to sevoflurane alone (Figure 3). TEA pre-treatment significantly decreased the $\mathrm{EC}_{50 \mathrm{r}}$ for sevoflurane $(6.2$ $\pm 0.8 \%$ versus $7.5 \pm 0.7 \%, P<0.01)$. In series $1 B(n=10$ rings per group), $1 \times 10^{-2} \mathrm{M}$ TEA caused marked but transient vasoconstriction, with a maximal contraction of 36.5 $\pm 3.1 \%$ attained 8 minutes following TEA addition (Figure 4). Prior incubation of rings with sevoflurane abolished the vasoconstrictor effect of TEA. This suggests that sevoflurane directly blocks the $\mathrm{K}_{\mathrm{Ca}++}$ channel, thereby occluding the effect of TEA.

In Series 2, blockade of the ATP sensitive $\mathrm{K}^{+}$channel $\left(\mathrm{K}_{\mathrm{ATP}}\right)$ channel $\left(\mathrm{n}=10\right.$ rings per group) with $1 \times 10^{-5} \mathrm{M}$ glibenclamide significantly increased sevoflurane-mediated vasodilation compared to sevoflurane alone (Figure 5). Glibenclamide pre-treatment significantly decreased the $\mathrm{EC}_{50 \mathrm{r}}$ for sevoflurane $(5.5 \pm 0.9 \%$ versus $6.8 \pm 1.0 \%, \mathrm{P}$ $<0.005)$.

\section{Sevoflurane and the $\mathbf{C a}^{++}$Channel}

In Series 3, blockade of the sarcolemmal voltage-operated $\mathrm{Ca}^{++}$channel ( $\mathrm{n}=10$ rings per group) with $1 \times 10^{-6} \mathrm{M}$ verapamil significantly inhibited sevoflurane-mediated vasodilation compared to sevoflurane alone (Figure 6). Verapamil pre-treatment significantly increased the $\mathrm{EC}_{50 \mathrm{r}}$ for sevoflurane $(9.8 \pm 1.1 \%$ versus $6.7 \pm 1.0 \%, \mathrm{P}<0.01)$. In Series $4 A$, blockade of the sarcolemmal voltage-independent $\mathrm{Ca}^{++}$channel with $3 \times 10^{-5} \mathrm{M} \mathrm{SK} \& \mathrm{~F} 96365$ ( $\mathrm{n}=10$ rings per group) did not alter sevoflurane-mediated vasodilation (data not presented). In Series $4 \mathrm{~B}$, higher concentrations $\left(1 \times 10^{-4} \mathrm{M}\right)$ of SK\&F $96365(\mathrm{n}=10$ rings per group) were similarly ineffective in altering sevoflu- 


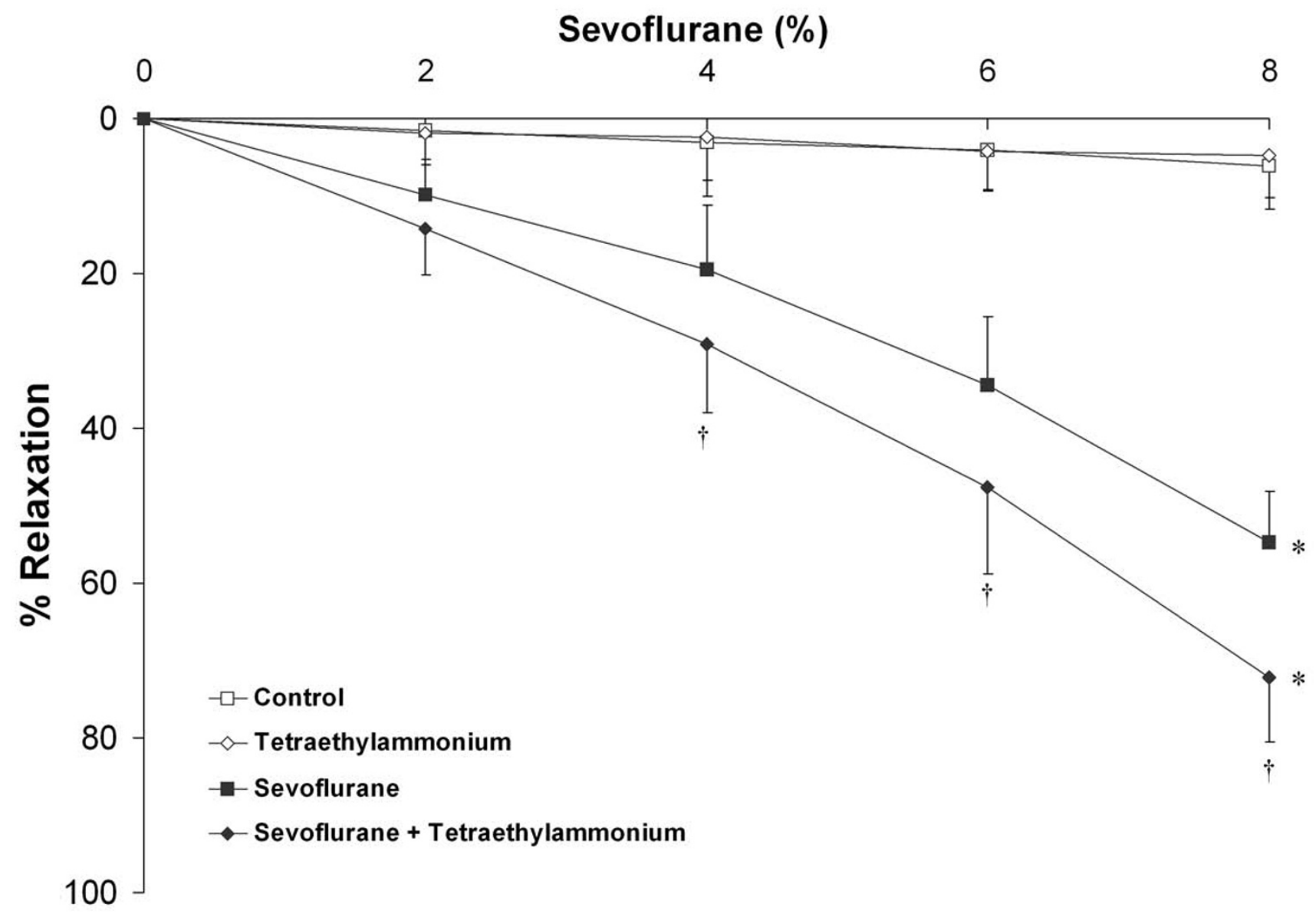

Figure 3

Blockade of $\mathbf{K}_{\mathrm{Ca}^{++}}$channels enhances the vasodilatory effect of sevoflurane. Sevoflurane produced significant dose dependent vasodilation of chorionic plate arterial rings compared to control conditions. Prior blockade of $\mathrm{K}_{\mathrm{Ca}^{+}+}$channels by incubation in $\mathrm{I} \times 10^{-2} \mathrm{M}$ tetraethylammonium $(\mathrm{n}=10$ rings per group) enhanced the vasodilatory effect of sevoflurane. *P $<$ 0.05 compared to rings exposed to control conditions. (Two way RM-ANOVA). $\dagger P<0.05$ compared to rings exposed to sevoflurane plus vehicle at graded sevoflurane concentrations (post hoc between group $t$ test).

rane-mediated vasodilation. (Figure 7), and did not alter the $\mathrm{EC}_{50 \mathrm{r}}$ for sevoflurane $(6.7 \pm 0.9 \%$ versus $6.9 \pm 1.0 \%, \mathrm{P}$ $=0.7$ ).

In Series $5 A$, blockade of the sarcoplasmic reticulum $\mathrm{Ca}^{++}$ channel with $5 \times 10^{-6} \mathrm{M}$ ryanodine $(\mathrm{n}=10$ rings per group) did not alter sevoflurane-mediated vasodilation (data not presented). In Series $5 \mathbf{B}$, higher concentrations $\left(5 \times 10^{-5} \mathrm{M}\right)$ of ryanodine $(\mathrm{n}=10$ rings per group) were similarly ineffective in altering sevoflurane-mediated vasodilation. (Figure 8), and did not alter the $\mathrm{EC}_{50 \mathrm{r}}$ for sevoflurane $(6.7 \pm 1.0 \%$ versus $6.8 \pm 0.9 \%, P=0.8)$.

\section{Discussion}

A substantial number of patients require general anaesthesia during pregnancy, for a variety of indications, including non-obstetric surgery [22]. In fact, the need for general anaesthesia during pregnancy may increase in future years, due to the emergence of in utero foetal surgical techniques, such as the ex utero intrapartum treatment (EXIT) procedure [23]. These procedures generally employ higher sevoflurane concentrations in order to produce uterine relaxation and facilitate in utero surgery, with concentrations of $4-5 \%$ sevoflurane reported for the EXIT procedure [24].

We have recently demonstrated that sevoflurane produces dose dependent vasodilation in the foeto-placental circulation in vitro [4]. These effects of sevoflurane are mediated via a mechanism that is NO-independent and which was mediated in part via the generation of lipoxygenase derived vasodilator prostanoids. However, blockade of the lipoxygenase enzyme does not abolish sevofluranemediated vasodilation, suggesting that other mechanisms 


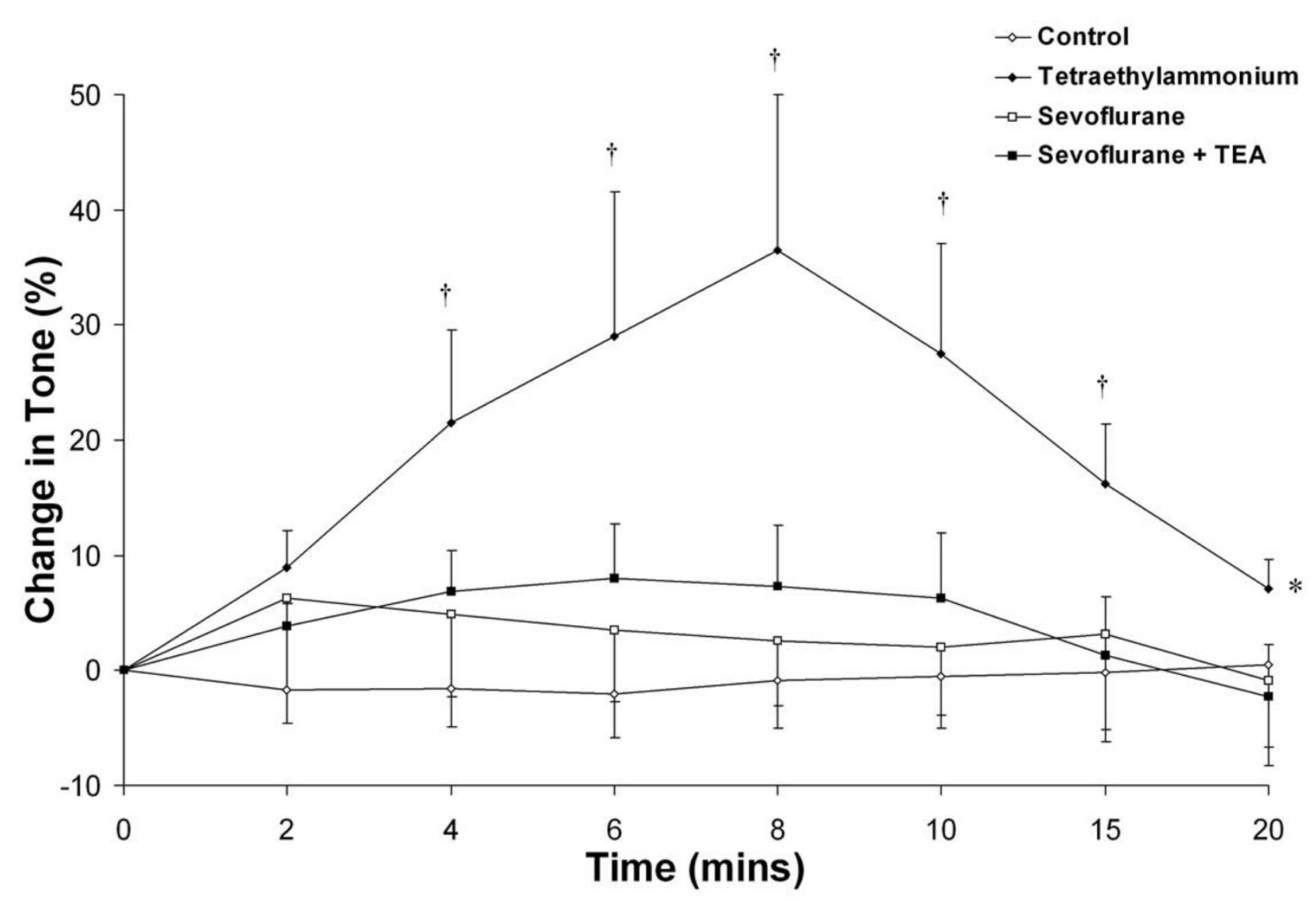

Figure 4

Prior exposure of chorionic rings to sevoflurane blocks the effect of tetraethylammonium. Exposure of rings to I $\times 10^{-2} \mathrm{M}$ tetraethylammonium transiently enhances resting tone. This effect is abolished following prior incubation in sevoflurane, demonstrating that sevoflurane blocks $\mathrm{K}_{\mathrm{C}^{++}}$channels $(\mathrm{n}=10$ rings per group). $* \mathrm{P}<0.05$ compared to control (Two way RM-ANOVA). $+P<0.05$ compared to control at each timepoint (post hoc between group $t$ test).

of action may contribute to this effect. One potential mechanism by which sevoflurane may produce vasodilation in this circulation would be via the modulation of ion channel function. The effects of volatile anaesthetic agents on $\mathrm{K}^{+}$channels appear to be agent and vascular bed specific. Halothane-mediated vasodilation of conducting and resistance coronary arteries is mediated via activation of the adenosine triphosphate-sensitive potassium $\left(\mathrm{K}_{\mathrm{ATP}}\right)$ channels [5]. In contrast, sevoflurane increases coronary collateral blood flow via mechanisms that appear to be independent of $\mathrm{K}_{\mathrm{ATP}}$ channel activation [7], but which involve activation of $\mathrm{K}_{\mathrm{Ca}++}$ channels [8]. These findings lead us to hypothesize that sevoflurane may produce vasodilation in the foeto-placental circulation via activation of $\mathrm{K}_{\mathrm{Ca}++}$ and/or $\mathrm{K}_{\mathrm{ATP}}$ channels.

Our findings demonstrate that sevoflurane did not produce vasodilation via activation of either the $\mathrm{K}_{\mathrm{Ca}++}$ or the
$\mathrm{K}_{\mathrm{ATP}}$ channel. In fact, prior exposure of the chorionic arterial rings to TEA, which blocks the $\mathrm{K}_{\mathrm{Ca++}}$ channels, and glibenclamide, which blocks the $\mathrm{K}_{\mathrm{ATP}}$ channel, clearly enhanced sevoflurane-mediated vasodilation. This suggests that sevoflurane in part inhibited or blocked these $\mathrm{K}^{+}$ channels, contrary to our contention. We wished to confirm that sevoflurane did indeed block the $\mathrm{K}_{\mathrm{Ca}++}$ and $\mathrm{K}_{\mathrm{ATP}}$ channels. If this contention were correct, then prior incubation of the rings with sevoflurane would prevent binding of agents that block these channels, and thereby abolish their effect. In further experiments, carried out to clarify this issue, blockade of $\mathrm{K}_{\mathrm{Ca++}}$ channels by TEA caused transient vasoconstriction, which demonstrates a role for the $\mathrm{K}_{\mathrm{Ca++}}$ channels in regulating vasomotor tone in the foeto-placental circulation. However, prior incubation of the rings with sevoflurane prior to exposure to TEA abolished this effect. Taken together, these findings indicate that sevoflurane blocks the $\mathrm{K}_{\mathrm{Ca}++}$ channel. These find- 


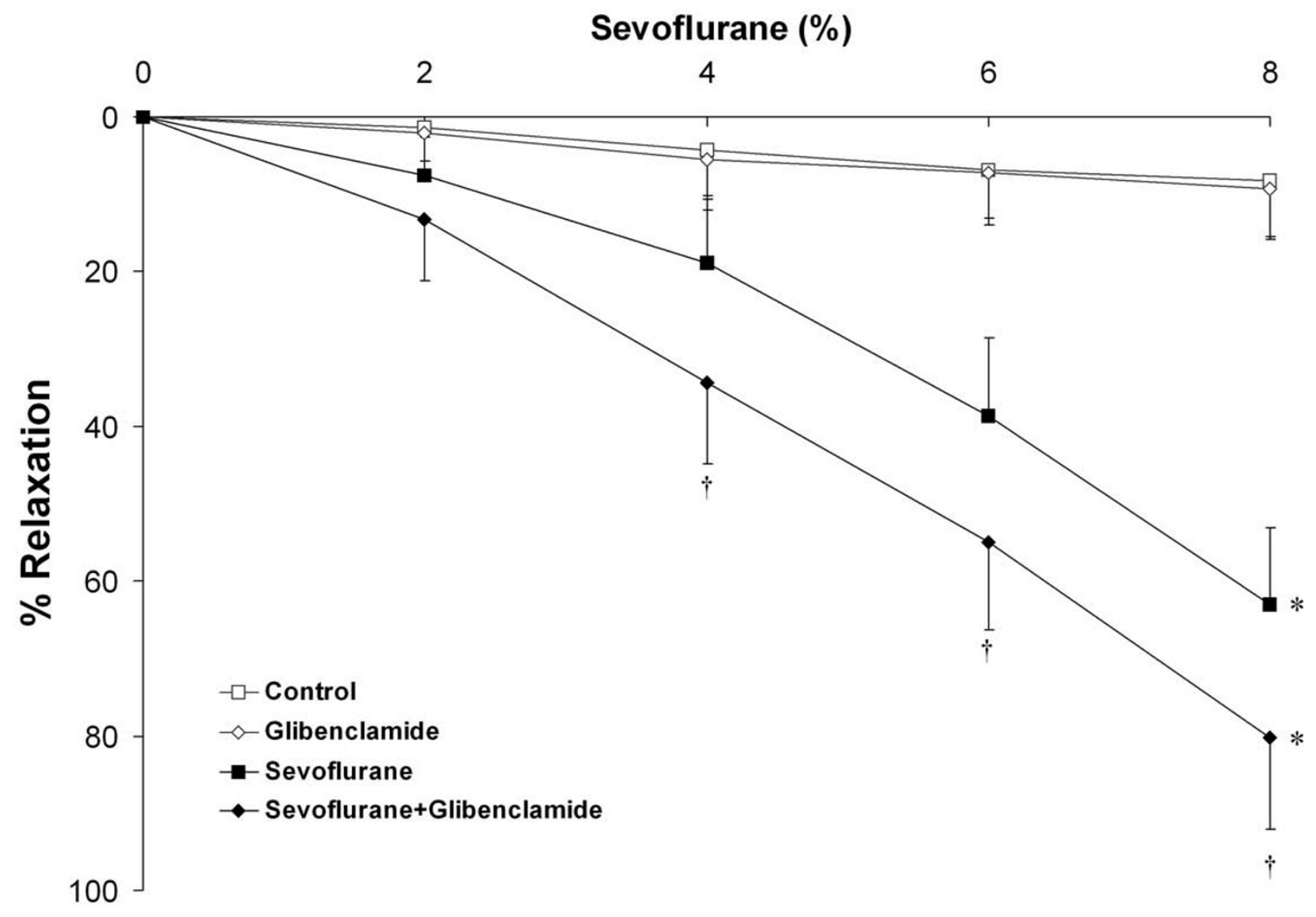

\section{Figure 5}

Blockade of $K_{A T P}$ channels enhances the vasodilatory effect of sevoflurane. Sevoflurane produced significant dose dependent vasodilation of chorionic plate arterial rings compared to control conditions. Prior blockade of $\mathrm{K}_{\mathrm{ATP}}$ channels by incubation in $\mathrm{I} \times 10^{-5} \mathrm{M}$ glibenclamide $(\mathrm{n}=10$ rings per group) enhanced the vasodilatory effect of sevoflurane. *P $<0.05$ compared to rings exposed to control conditions. (Two way RM-ANOVA). $\dagger P<0.05$ compared to rings exposed to sevoflurane plus vehicle at graded sevoflurane concentrations (post hoc between group $t$ test).

ings are not inconsistent with previous literature. Halothane has been demonstrated to depress the function of a wide variety of both invertebrate and mammalian $\mathrm{K}^{+}$ channels [25], including the $\mathrm{K}_{\mathrm{Ca}++}$ channel in rodents [26], and in canine cerebral and coronary vascular smooth muscle [27]. Our findings emphasise the potential for volatile anaesthetic agent to exert effects on vascular bed specific the $\mathrm{K}_{\mathrm{Ca}++}$ or the $\mathrm{K}_{\mathrm{ATP}}$ channel.

Our second hypothesis was that sevoflurane produced vasorelaxation in part via the blockade of calcium ion channels. We therefore examined the potential for the effects of sevoflurane to be mediated via the sarcolemmal voltage-operated $\mathrm{Ca}^{++}$channel (VOCC) [9], the sarcolemmal voltage-independent $\mathrm{Ca}^{++}$channels (VICC) $[9,10]$, and/or the sarcoplasmic reticulum calcium channel. Our findings demonstrate that sevoflurane produced vasodilation, at least in part, via an effect on the sarcolemmal voltage-operated calcium channel (VOCC). Prior incubation with the VOCC channel blocker verapamil, at concentrations similar to that previously reported $[17,18]$, significantly inhibited sevoflurane-mediated vasodilation of the pre-constricted chorionic plate arterial rings. These findings demonstrate that sevoflurane-mediated vasodilation in this circulation is dependent in part on a blocking effect at the VOCC channel. This effect of sevoflurane would reduce intracellular calcium influx, and thereby reduce chorionic plate arterial vasomotor tone. In contrast, the vasomotor effects of sevoflurane appear to be independent of both the sarcolemmal voltage-independent calcium channel and alterations in sarcoplasmic reticulum calcium release. 


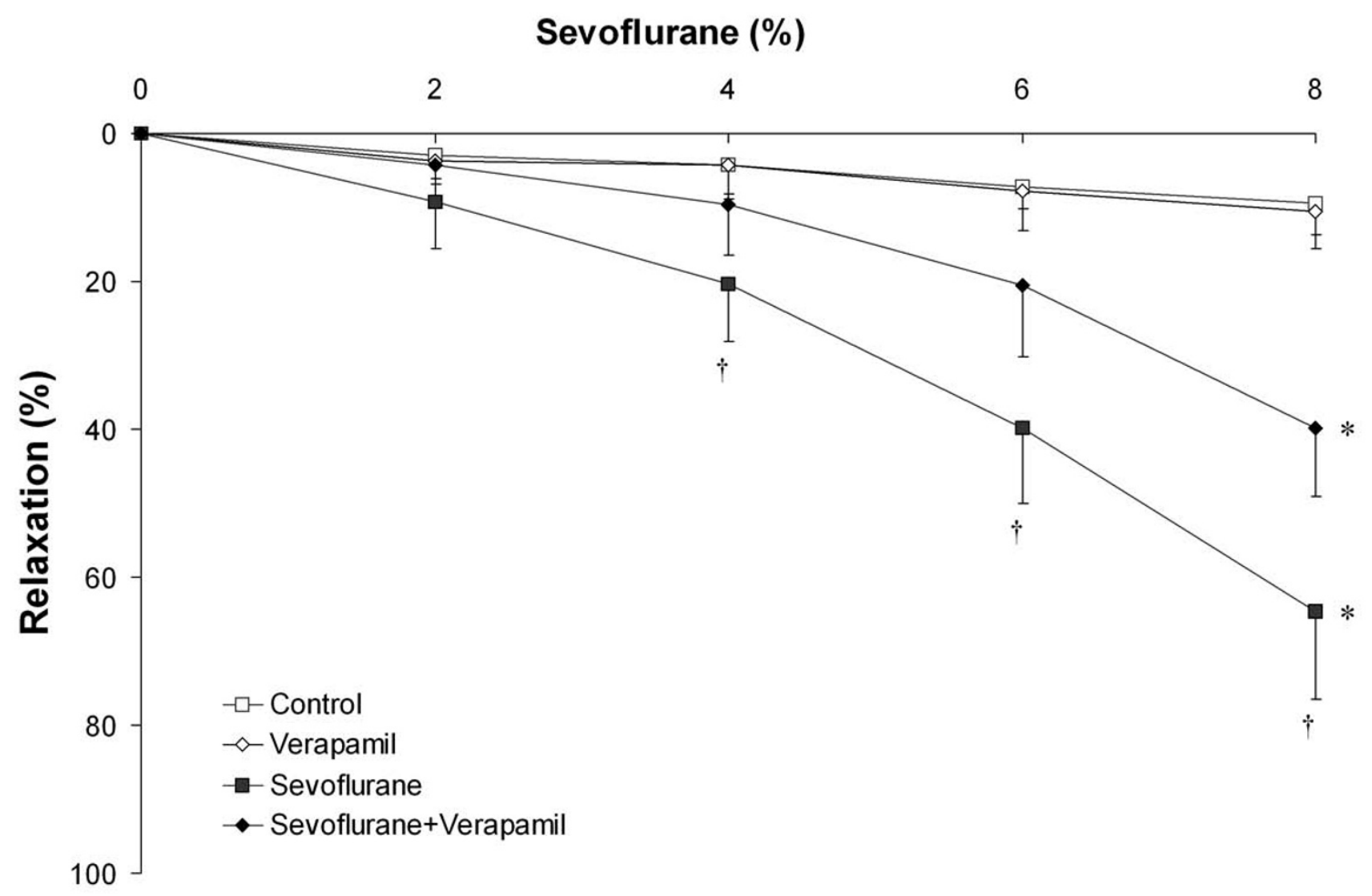

Figure 6

Blockade of sarcolemmal voltage-operated $\mathrm{Ca}^{++}$channel (VOCC) attenuates the vasodilatory effect of sevoflurane. Sevoflurane produced significant dose dependent vasodilation of chorionic plate arterial rings compared to control conditions. Prior blockade of VOCC's by incubation in $1 \times 10^{-6} \mathrm{M}$ verapamil $(n=10$ rings per group $)$ reduced the vasodilatory effect of sevoflurane. *P $<0.05$ compared to rings exposed to control conditions. (Two way RM-ANOVA). $\nmid \mathrm{P}<0.05$ compared to rings exposed to sevoflurane plus verapamil at graded sevoflurane concentrations (post hoc between group $t$ test).

It is clear, based on these findings, and those of our prior study [4], that sevoflurane modulates vasomotor tone in the foeto-placental circulation via a number of separate and competing mechanisms. Sevoflurane inhibits the production of vasodilator prostanoids, and also inhibits the activity of the $\mathrm{K}_{\mathrm{Ca}++}$ and $\mathrm{K}_{\mathrm{ATP}}$ channels, which would act to increase vascular tone. However, these effects are counterbalanced by sevoflurane-mediated inhibition of vasoconstrictor eicosanoid production, and blockade of $\mathrm{Ca}^{++}$ channels, which act to produce vasodilation. The net effect of these contrasting mechanisms of action is to produce dose-dependent vasodilation. Of interest, halothane has been demonstrated to exert similar effects on ion channel function in isolated smooth muscle cells of canine cerebral arteries [28], and in canine coronary arterial cells [29]
There are some limitations to this study. Firstly, these studies are conducted in second order chorionic plate arteries. Characterisation of the effects of sevoflurane on smaller vessels in the foeto-placental circulation (i.e. placental resistance arteries) is also required. Secondly, chorionic plate arterial ring samples were obtained from healthy parturients. Characterisation of the effects of sevoflurane in the setting of compromised utero-placental circulation, in which foetal hypoxia may be more prevalent would add further useful information. Thirdly, SK\&F 96365, which was utilised to determine the role of the voltage-independent $\mathrm{Ca}^{++}$channels in mediating the vasorelaxant effect of sevoflurane, may also have a weak VOCC blocking action $[9,10]$. However, these effects are only seen at higher concentrations that were used in these studies, and in any case SK\&F 96365 did not modulate the 


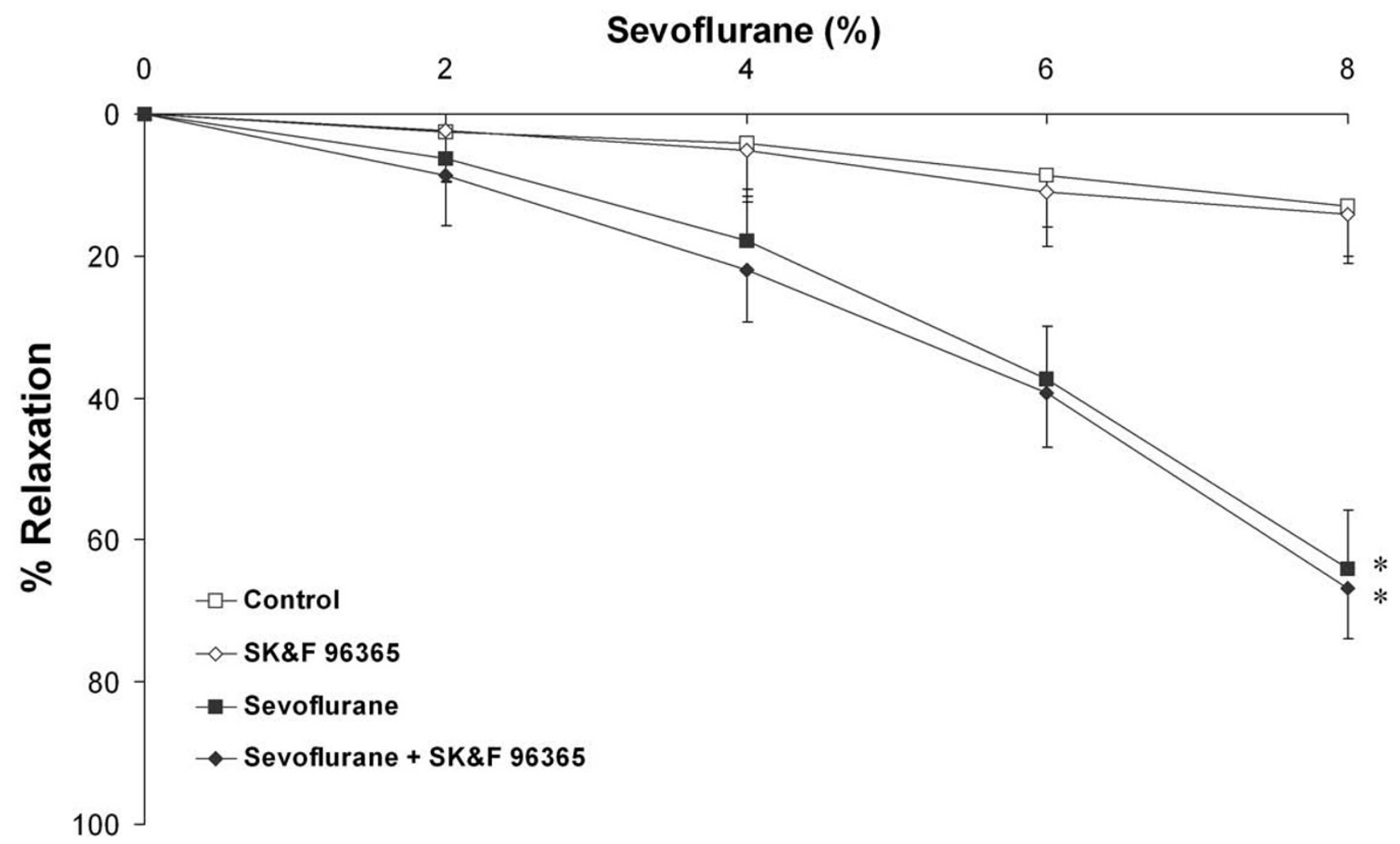

Figure 7

Blockade of sarcolemmal voltage-independent $\mathrm{Ca}^{++}$channels (VICC), by prior incubation with I $\times 10^{-4} \mathrm{M}$ SK\&F 96365 ( $n=10$ rings per group), does not alter sevoflurane mediated vasodilation. Sevoflurane produced significant dose dependent vasodilation compared to control conditions, which was not modulated by SK\&F 96365 . *P < 0.05 compared to rings exposed to control conditions. (Two way RM-ANOVA).

effect of sevoflurane in these studies. Fourthly, our findings may not apply to other inhaled anaesthetic agents, especially in a quantitative manner. The effects of other volatile anaesthetics will need to be separately determined. Fifthly, these experiments were conducted under conditions of hyperoxia, in contrast to the hypoxic conditions normally experienced by the placental circulation. Hyperoxia may cause vasoconstriction in this circulation. However the oxygen levels used in these studies are widely used in isolated placental vessel preparations [30-32]. Perfusate oxygen tensions were the same across all experimental groups in this study. Therefore, the impact of the oxygen concentrations in these experiments is likely to have been limited. Finally, there are limitations in extrapolating from in vitro experiments to the in vivo situation.

\section{Conclusion}

We conclude that sevoflurane dose dependently dilates the foeto-placental vasculature, by a mechanism mediated in part via blockade of the voltage-operated calcium channel, in this isolated placental vessel model. Further study is required to investigate determine the clinical significance of these findings.

\section{Abbreviations}

ANOVA: analysis of variance; ATP: Adenosine triphosphate; $\mathrm{Ca}^{++}$: Calcium ion; $\mathrm{CaCl}_{2}$ : Calcium chloride; $\mathrm{EC}_{50 \mathrm{r}}$ : concentration required dilate rings by 50\%; EXIT: ex utero intrapartum treatment procedure; HIV: Human Immunodeficiency virus; $\mathrm{K}^{+}$: Potassium ion; $\mathrm{K}_{\mathrm{ATP}}$ : ATP sensitive $\mathrm{K}^{+}$ channel; $\mathrm{K}_{\mathrm{Ca}_{+}+}$: calcium-activated $\mathrm{K}^{+}$channel; $\mathrm{KCl}$ : Potassium Chloride; $\mathrm{kPa}$ : kilopascals; $\mathrm{M}$ : molar; $\mathrm{MgSO}_{4} ; \mathrm{NaCl}$ : Sodium Chloride; $\mathrm{NaHCO}_{3}$ : sodium bicarbonate; $\mathrm{Na}_{2} \mathrm{HPO}_{4}$ : sodium hydrogen phosphate; NO: nitric oxide; $\mathrm{P}_{\mathrm{CO} 2}$ : Partial pressure of carbon dioxide; $\mathrm{P}_{\mathrm{O} 2}$ : Partial pressure of oxygen; PSS: physiologic saline solution; Sevo: sevoflurane; SD: standard deviation; TEA: Tetraethylammonium; U46619: 9,11-dideoxy-11 $\alpha, 9 \alpha$-epoxymethano- 


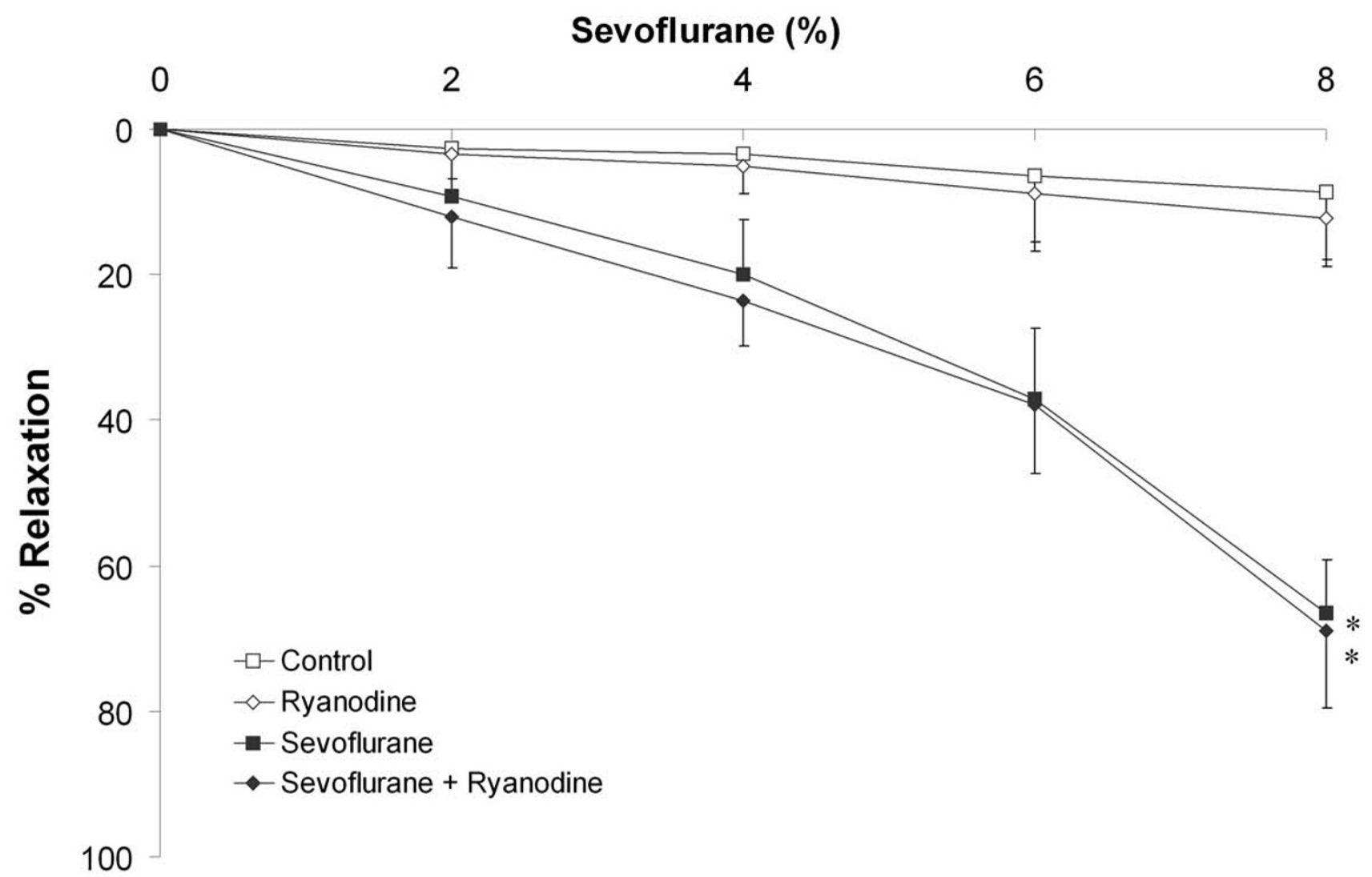

Figure 8

Blockade of sarcoplasmic reticulum $\mathrm{Ca}^{++}$channel, by prior incubation with $5 \times 10^{-5} \mathrm{M}$ ryanodine $(\mathrm{n}=10$ rings per group), does not alter sevoflurane mediated vasodilation. Sevoflurane produced significant dose dependent vasodilation compared to control conditions, which was not modulated by ryanodine. ${ }^{*} \mathrm{P}<0.05$ compared to rings exposed to control conditions. (Two way RM-ANOVA).

prostagladin $\mathrm{F}_{2 \alpha} ; \quad$ VICC: voltage-independent $\mathrm{Ca}^{++}$ channels; VOCC: voltage-operated $\mathrm{Ca}^{++}$channel.

\section{Competing interests}

The authors declare that they have no competing interests.

\section{Authors' contributions}

$\mathrm{CHM}$ and BDH conceived of the study, and participated in its design and execution and helped to draft the manuscript. JJ, and RFF performed experiments, and helped to draft the manuscript. CDL determined concentrations of sevoflurane in the perfusate using gas chromatographymass spectrometric analyses. NMF and JGL participated in the design and coordination of the study, performed the statistical analysis, and helped to draft the manuscript. All authors read and approved the final manuscript.

\section{Acknowledgements}

This study was part funded by the Millennium Fund, NUI Galway, Ireland, the Yamanouchi European Foundation, and the Health Research Board (Ireland). The authors wish to extend their gratitude to the staff of the delivery suite at Galway University Hospital, for their help and cooperation in obtaining placental tissue.

\section{References}

I. Gambling DR, Sharma SK, White PF, Van Beveren T, Bala AS, Gouldson R: Use of sevoflurane during elective cesarean birth: a comparison with isoflurane and spinal anesthesia. Anesth Analg 1995, 8 I ( I):90-95.

2. Chin KJ, Yeo SW: Bispectral index values at sevoflurane concentrations of $1 \%$ and $1.5 \%$ in lower segment cesarean delivery. Anesth Analg 2004, 98(4): I I 40-1 I 44.

3. Chin KJ, Yeo SW: A BIS-guided study of sevoflurane requirements for adequate depth of anaesthesia in Caesarean section. Anaesthesia 2004, 59(I I): 1064-1068.

4. Farragher R, Maharaj $C H$, Higgins $B D$, Crowe S, Burke P, Laffey $C D$, Flynn NM, Laffey JG: Sevoflurane and the feto-placental vascu- 
lature: the role of nitric oxide and vasoactive eicosanoids. Anesth Analg 2008, 107(I): 17I-I77.

5. Larach DR, Schuler HG: Potassium channel blockade and halothane vasodilation in conducting and resistance coronary arteries. J Pharmacol Exp Ther 1993, 267(I):72-81.

6. Chrissobolis S, Sobey CG: Inwardly rectifying potassium channels in the regulation of vascular tone. Curr Drug Targets 2003, 4(4):28I-289.

7. Kersten JR, Schmeling T, Tessmer J, Hettrick DA, Pagel PS, Warltier DC: Sevoflurane selectively increases coronary collateral blood flow independent of KATP channels in vivo. Anesthesiology 1999, 90(I):246-256.

8. Kehl F, Krolikowski JG, Tessmer JP, Pagel PS, Warltier DC, Kersten JR: Increases in coronary collateral blood flow produced by sevoflurane are mediated by calcium-activated potassium (BKCa) channels in vivo. Anesthesiology 2002, 97(3):725-73।.

9. Vinh VH, Enoki T, Hirata S, Toda $\mathrm{H}$, Kakuyama M, Nakamura $\mathrm{K}$, Fukuda K: Comparative contractile effects of halothane and sevoflurane in rat aorta. Anesthesiology 2000, 92(I):219-227.

10. Komuro T, Miwa S, Zhang XF, Minowa T, Enoki T, Kobayashi S, Okamoto Y, Ninomiya H, Sawamura T, Kikuta K, et al.: Physiological role of $\mathrm{Ca2+-permeable} \mathrm{nonselective} \mathrm{cation} \mathrm{channel} \mathrm{in}$ endothelin-I-induced contraction of rabbit aorta. J Cardiovasc Pharmacol 1997, 30(4):504-509.

II. Loughrey JP, Laffey JG, Moore BJ, Lynch F, Boylan JF, McLoughlin P: Interleukin-I b rapidly inhibits aortic endothelium-dependent relaxation by a DNA transcription-dependent mechanism. Critical Care Medicine 2003, 3 I(3):910-5.

12. Fukushima T, Hirasaki A, Jones KA, Warner DO: Halothane and potassium channels in airway smooth muscle. $\mathrm{Br} J$ Anaesth 1996, 76(6):847-853.

13. Akata T, Izumi K, Nakashima M: The action of sevoflurane on vascular smooth muscle of isolated mesenteric resistance arteries (part 2): mechanisms of endothelium-independent vasorelaxation. Anesthesiology 2000, 92(5): | 44|-| 453 .

14. Izumi K, Akata T, Takahashi S: The action of sevoflurane on vascular smooth muscle of isolated mesenteric resistance arteries (part I): role of endothelium. Anesthesiology 2000, 92(5): $1426-1440$.

15. Lindauer U, Vogt J, Schuh-Hofer S, Dreier JP, Dirnagl U: Cerebrovascular vasodilation to extraluminal acidosis occurs via combined activation of ATP-sensitive and $\mathrm{Ca2+-activated}$ potassium channels. J Cereb Blood Flow Metab 2003, 23(10): I227-1238.

16. Nakahata $\mathrm{K}$, Kinoshita $\mathrm{H}$, Hirano $\mathrm{Y}$, Kimoto $\mathrm{Y}$, Iranami $\mathrm{H}$, Hatano $\mathrm{Y}$ : Mild hypercapnia induces vasodilation via adenosine triphosphate-sensitive $\mathbf{K +}$ channels in parenchymal microvessels of the rat cerebral cortex. Anesthesiology 2003, 99(6): 1333-1339.

17. Atalik KE, Kilic M, Nurullahoglu ZU, Dogan N: Effects of cooling on histamine-induced contractions of human umbilical artery: the role of ion channels. Methods Find Exp Clin Pharmacol 2007, 29(9):619-623.

18. Resch BE, Gaspar R, Falkay G: Application of electric field stimulation for investigations of human placental blood vessels. Obstet Gynecol 2003, 10 I (2):297-304.

19. Tanaka Y, Imai T, Igarashi T, Takayanagi K, Otsuka K, Yamaki F, Tanaka H, Shigenobu K: Comparison of the Ca2+ entry channels responsible for mechanical responses of guinea-pig aorta to noradrenaline and thapsigargin using SK\&F 96365 and LOE 908. Naunyn Schmiedebergs Arch Pharmacol 2000, 362(2): 160-168.

20. Long W, Zhang L, Longo LD: Cerebral artery sarcoplasmic reticulum $\mathrm{Ca}(2+)$ stores and contractility: changes with development. Am J Physiol Regul Integr Comp Physiol 2000, 279(3):R860-873.

21. Pourmahram GE, Snetkov VA, Shaifta Y, Drndarski S, Knock GA, Aaronson $\mathrm{PI}, \mathrm{W}$ ard JP: Constriction of pulmonary artery by peroxide: role of $\mathrm{Ca}(2+)$ release and PKC. Free Radic Biol Med 2008 , 45(10): I $468-76$

22. Brodsky JB, Cohen EN, Brown BW Jr, Wu ML, Whitcher C: Surgery during pregnancy and fetal outcome. Am J Obstet Gynecol 1980, 138(8): $1165-1167$.

23. Schwarz U, Galinkin JL: Anesthesia for fetal surgery. Semin Pediatr Surg 2003, I2(3): | 96-201.

24. Ducloy-Bouthors AS, Marciniak B, Vaast P, Fayoux P, HoufflinDebarge $\mathrm{V}$, Fily A, Rakza T: [Maternal and foetal anaesthesia for ex utero intrapartum treatment (EXIT) procedure]. Ann $\mathrm{Fr}$ Anesth Reanim 2006, 25(6):638-643.

25. Zorn L, Kulkarni R, Anantharam V, Bayley H, Treistman SN: Halothane acts on many potassium channels, including a minimal potassium channel. Neurosci Lett 1993, I6 I(I):8I-84.

26. Gin T, Chan MT: Decreased minimum alveolar concentration of isoflurane in pregnant humans. Anesthesiology 1994, 8I(4):829-832.

27. Marijic J, Buljubasic N, Coughlan MG, Kampine JP, Bosnjak ZJ: Effect of $\mathrm{K}+$ channel blockade with tetraethylammonium on anesthetic-induced relaxation in canine cerebral and coronary arteries. Anesthesiology 1992, 77(5):948-955

28. Buljubasic N, Flynn NM, Marijic J, Rusch NJ, Kampine JP, Bosnjak Z]: Effects of isoflurane on $\mathrm{K}+$ and $\mathrm{Ca}+$ conductance in isolated smooth muscle cells of canine cerebral arteries. Anesth Analg 1992, 75(4):590-596

29. Buljubasic N, Rusch NJ, Marijic J, Kampine JP, Bosnjak Z]: Effects of halothane and isoflurane on calcium and potassium channel currents in canine coronary arterial cells. Anesthesiology 1992, 76(6): $990-998$.

30. Garcia-Huidobro DN, Garcia-Huidobro MT, Huidobro-Toro JP: Vasomotion in human umbilical and placental veins: role of gap junctions and intracellular calcium reservoirs in their synchronous propagation. Placenta 2007, 28(4):328-338.

31. Kwek K, Read MA, Khong TY, Bisits AT, Walters WA: Vasoactive effects of 8-epi-prostaglandin $F(2$ alpha)in isolated human placental conduit and resistance blood vessels in vitro. Placenta 200I, 22(6):526-533.

32. Sand $A E$, Andersson E, Fried G: Effects of nitric oxide donors and inhibitors of nitric oxide signalling on endothelin- and serotonin-induced contractions in human placental arteries. Acto Physiol Scand 2002, I74(3):217-223.

\section{Pre-publication history}

The pre-publication history for this paper can be accessed here:

http://www.biomedcentral.com/1471-2253/9/4/prepub

Publish with BioMed Central and every scientist can read your work free of charge

"BioMed Central will be the most significant development for disseminating the results of biomedical research in our lifetime. "

Sir Paul Nurse, Cancer Research UK

Your research papers will be:

- available free of charge to the entire biomedical community

- peer reviewed and published immediately upon acceptance

- cited in PubMed and archived on PubMed Central

- yours - you keep the copyright 